\title{
Genetic polymorphisms of Th2 interleukins, history of asthma or eczema and childhood acute lymphoid leukaemia: findings from the ESCALE study (SFCE)
}

Bonaventure A ${ }^{a, b, c}$, Orsi L ${ }^{a}$, Rudant ${ }^{\mathrm{a}}{ }^{\mathrm{a}, \mathrm{b}}$, Goujon-Bellec $\mathrm{S}^{\mathrm{a}, \mathrm{b}}$, Leverger $\mathrm{G}^{\mathrm{d}}$, Baruchel A ${ }^{\mathrm{e}}$, Bertrand $\mathrm{Y}$ ${ }^{\mathrm{f}}$, Nelken B ${ }^{\mathrm{g}}$, Pasquet $\mathrm{M}^{\mathrm{h}}$, Michel $\mathrm{G}^{\mathrm{i}}$, Sirvent $\mathrm{N}^{\mathrm{j}}$, Chastagner $\mathrm{P}^{\mathrm{k}}$, Ducassou $\mathrm{S}^{1}$, Thomas $\mathrm{C}^{\mathrm{m}}$, Besse C n, Hémon D a, Clavel J a,b.

a INSERM, Université Paris-Descartes, Université Sorbonne-Paris-Cité, CRESS U1153, EPICEAEpidémiologie des cancers de l'enfant et de l'adolescent, Villejuif, France

${ }^{\mathrm{b}}$ INSERM, RNCE-National Registry of Childhood Cancers, Villejuif, France

${ }^{\mathrm{c}}$ Cancer Survival Group, Department of Non-Communicable Disease Epidemiology, London School of Hygiene \& Tropical Medicine, London, United Kingdom

d AP-HP, Hôpital Armand Trousseau, Université Paris 6 Pierre et Marie Curie, Paris, France

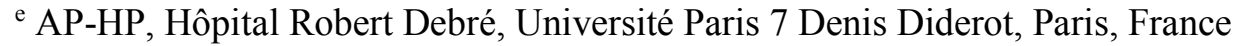

${ }^{\mathrm{f}}$ Institut d'Hémato-Oncologie Pédiatrique, Lyon, France

${ }^{\mathrm{g}}$ CHU de Lille, Hôpital Jeanne de Flandre, Lille, France

${ }^{\text {h }}$ Hôpital des Enfants, Toulouse, France

${ }^{i}$ AP-HM, Hôpital la Timone, Marseille, France

${ }^{j}$ Hôpital Arnaud de Villeneuve, CHRU, Montpellier, France

${ }^{\mathrm{k}} \mathrm{CHU}$ de Nancy, Vandoeuvre, France

${ }^{1}$ Haematology and Oncology; Childrens' Hospital, Pellegrin, Bordeaux University Hospital, Bordeaux, France

${ }^{\mathrm{m}}$ Service d'onco-hématologie pédiatrique, $\mathrm{CHU}$ de Nantes, France

${ }^{\mathrm{n}}$ Commissariat à l'Energie Atomique (CEA) Genomics Institute-Centre National de Génotypage, Evry Cedex, France

Corresponding author: Dr Audrey Bonaventure

16, Avenue Paul Vaillant-Couturier

Bâtiment 15/16

94807 Villejuif Cedex

France

Present address:

London School of Hygiene and Tropical Medicine,

Keppel Street

WC1E 7HT London

United Kingdom

audrey.bonaventure@1shtm.ac.uk

Tel : +44 2079272123

\section{Submitted as a Research article}

Short title: Genetic polymorphisms of interleukins, history of asthma or eczema and childhood leukaemia 
Keywords: epidemiology; childhood leukaemia; gene-environment interactions; allergy; asthma; cytokines

\section{Abreviations}

ALL Acute lymphoid leukaemia

OR Odds ratio

SNPs Single nucleotide polymorphisms

IL Interleukins

Declaration of interests: none

\section{Authors email addresses:}

Audrey.bonaventure@inserm.fr; Audrey.bonaventure@1shtm.ac.uk

\section{Highlights word count: 63}

\section{Abstract word count: 239}

\section{Word count: 3505}

\section{Tables: 5}

Figures: 0 


\section{Abstract (239 words)}

Background: Previous studies on the putative role of allergy in the aetiology of childhood leukaemia have reported contradictory results. The present study aimed to analyse the relation between a medical history of asthma or eczema and childhood acute lymphoid leukaemia (ALL) in light of potential candidate gene-environment interactions.

Methods: Analyses were based on a subset of 434 cases of ALL and 442 controls successfully genotyped and of European ancestry children enrolled in a French population-based case-control study conducted in 2003-2004. Information about medical history was obtained during a standardized interview with the mothers. Candidate polymorphisms in genes of the Th2 cytokines IL4, IL10, IL13 and IL4-receptor, were genotyped or imputed.

Results: None of the variant alleles were directly associated with childhood acute lymphoid leukaemia. A medical history of asthma or eczema was reported more often in the control group $(\mathrm{OR}=0.7[0.5-1.0])$. This association was mostly seen in the group of children not carrying the IL13rs20541 variant allele (Interaction Odds Ratio IOR 1.9, p-interaction=0.07) and in those carrying the IL10 triple variant haplotype (IOR 0.5 , p-interaction $=0.04$ ). No interaction was observed with the candidate polymorphisms in $I L 4$ and $I L 4 R$.

Conclusion: This study provides a new insight into the relationship between allergic symptoms and childhood acute lymphoid leukaemia, by suggesting this inverse association could be limited to children carrying certain genetic polymorphisms. If confirmed, these results could help better understand the biological mechanisms involved in the development of childhood acute lymphoid leukaemia. 


\section{Introduction}

Acute lymphoid leukaemia (ALL) accounts for approximately $80 \%$ of all childhood acute leukaemias and a quarter of all childhood neoplasms in developed countries. Little risk factors have been identified to date, i.e. high-level ionizing radiation, certain chemotherapeutic agents, Down's syndrome and a few rare genetic disorders. It has long been hypothesized that a lack of immune stimulation through exposure to infectious agents in infancy and early childhood could be related to the development of $\mathrm{ALL}^{1}$, although the epidemiological evidence is still contradictory ${ }^{2}$. To some extent, this parallels the hygiene hypothesis, which postulates that a lack of early immune stimulation could be associated with the rising incidence of allergies in developed countries. From these, one could expect atopy and allergy to be positively associated with childhood leukaemia. However, most questionnaire-based epidemiological studies reported an inverse association between atopy or allergy and childhood leukaemia, as reviewed by Linabery ${ }^{3,4}$.

In the last few years, in an attempt to rely on unbiased sources of information, several publications have studied the association between atopy or allergy and childhood leukemia relying on objective sources of information, such as medical records ${ }^{5,6}$, health claim data ${ }^{7}$, and IgE levels at recruitment ${ }^{8}$. Some of those studies ${ }^{5,8}$ corroborated the inverse association between allergy and childhood leukaemia found in the interview-based studies, whereas two other studies did not find this association $^{6,7}$. Recently, a Mexican study reported a positive association borderline of significance between bronchial asthma and ALL in children with Down syndrome 9 .

Despite the increasing biological knowledge, the mechanisms leading to allergy still need to be unraveled. A role of Th2 cytokines has long been suspected in the etiology of allergy, supported by the key regulatory effects of the interleukins produced by T-lymphocytes undergoing a Th2 differentiation, such as interleukins (IL) IL4, IL10 and IL13. Additionally, some studies have reported associations between asthma and polymorphisms in the genes coding for IL13, IL4, IL10 and IL4R ${ }^{10-}$ 13. Polymorphisms in $I L 13$ and $I L 4 R$ were also associated with allergic rhinitis, wheeze atopic dermatitis in an international study ${ }^{14}$.

The role of interleukins in childhood leukaemia has been little investigated. In a Californian study, the levels of IL10 at birth were significantly lower in ALL cases than in controls ${ }^{15}$. In the same study, a genomic analysis showed a slight association between ALL and IL10 tag-SNPs (Single Nucleotide Polymorphisms) $)^{16}$. Recently, two polymorphisms in IL10 were reported to be associated with childhood leukaemia in Taiwan ${ }^{17}$.

The aim of the present study was to provide a new insight in the relationship between allergic disorders and childhood ALL by taking into account genetic polymorphisms of several Th2 cytokines, 
namely interleukins IL4, IL10, IL13 and IL4-receptor, suspected to be involved in the development of allergy.

\section{Material and methods}

\subsection{Study}

Study design and sampling have been extensively described elsewhere ${ }^{18,}{ }^{19}$. Briefly, the ESCALE study is a population-based case-control study conducted in France in 2003-2004. Eligible children were residing in mainland France, had not been adopted, and had a living French-speaker biological mother without a serious psychiatric disorder.

Children diagnosed with leukaemia before the age of 15 , between $01 / 01 / 2003$ and $31 / 12 / 2004$, were detected and recruited using the detection system of the French national childhood haematological malignancies registry. Children who were deceased or under palliative care were ineligible. Out of the 714 eligible children diagnosed with acute lymphoid leukaemia, 648 were enrolled in the study (participation rate $91 \%$ ).

Controls were randomly selected from the general population using random digit dialing contemporaneously with the recruitment of the cases. Quotas were applied to obtain a control group comparable to the whole case group (leukaemias, lymphomas, CNS tumours and neuroblastomas) in terms of gender and age $(0-1,2,3,4,5-6,7-8,9-11,12-14$ years $)$ and to the general population regarding the number of children living in the household. The participation rate of the controls was $71 \%$, so that 1,681 controls were enrolled out of the 2,361 eligible children.

\subsection{Information on medical history}

Information about socio-demographic characteristics and suspected risk factors, such as maternal exposures during pregnancy, perinatal characteristics, personal and familial medical history was obtained over the telephone. The children biological mothers were interviewed using a standardized questionnaire identical for cases and controls. Before the interview, mothers were asked to have a copy of the child health record on hand, so they could get back to the records if needed. A large proportion of mothers followed this recommendation (97.2\% for ALL cases and 98.2\% for controls). Mothers were specifically asked whether the participating child had developed asthma or eczema, and, if so, the age at onset. Moreover, a specific item regarded regular intakes of bronchodilators, corticoids, or antihistamines/anti-allergic drugs.

Reported medical history of asthma and eczema were analysed as independent variables. More specific variables were also analysed, considering a latency period of one year by ignoring the asthma 
or eczema diagnoses that occurred in the year prior to the age at diagnosis (for cases) or recruitment for controls).For asthma, we also considered the reported treatments with antihistamines, corticoids or bronchodilators. 


\subsection{Biological specimens}

Biological specimens were requested from each participant. They consisted in blood samples taken from cases during care, prior to initiation of chemotherapy, and saliva taken at home using swab brushes for the controls. Biological samples were obtained from 619 ALL cases (96\%) and 810 controls $(48 \%)$.

After DNA extraction, a sufficient DNA quantity was available for genotyping of 513 ALL cases and 570 controls. Cases were genotyped on an Illumina 370k Quad platform $(283,027$ single nucleotide polymorphisms [SNPs]), and a custom iSelect platform (4,868 SNPs) was used for the controls. The comparability of the two genotyping methods was assessed and confirmed by re-genotyping 96 randomly-selected cases on the platform used for the controls (100\% agreement). Fulfilled quality checks, including a call-rate $>97 \%$ for the cases and $95 \%$ for the controls, and a $46, \mathrm{XX}$ or $46, \mathrm{XY}$ formula were considered mandatory criteria for subsequent genetic analyses, leading to the exclusion of 42 ALL cases (including 6 children with Down syndrome) and 109 controls.

A principal component analysis (PCA) using information from 96,609 SNPs was performed in the case group in order to determine the Caucasian origin from the CEPH (Human Polymorphism Study Center). Because of the platform used for genotyping the controls, such a PCA could not be performed for the control group. However, in the case group, having at least two European-born grandparents, a proxy variable derived from the questionnaire, showed to be very predictive of the CEPH classification (sensitivity $98.2 \%$, specificity $94.3 \%$ ) $^{20}$. Assuming that this proxy variable was as good a predictor in the control group, it was used to restrict both the case and control samples on European ancestry, in order to limit the potential for population stratification bias.

Finally, 434 cases with ALL and 442 controls, all genotyped children of European ancestry $(\geq 2$ grandparents born in Europe), were available for the present analysis.

\subsection{Genotyping of candidates SNPS}

Polymorphisms in Th2 cytokines genes (IL4, IL10, IL13 and IL4R) were identified through a literature search and selected a priori as a sample of SNPs having been reported to be associated with allergy, asthma $^{10-13}$, or with IgE level ${ }^{14}$. Additional selection criteria were the effect of the genotype on the protein function or production level, and its availability after genotyping. Those polymorphisms selected for analysis were the haplotype rs2070874-rs2243250 in IL4, rs20541 in IL13, rs1801275 in IL4R and the haplotype rs1800896-rs1800871-rs1800872 in IL10.

The polymorphisms that could not be genotyped on the cases' platform, namely IL4-rs2070874 and rs2243250, IL10-rs1800871 and rs1800872, or that showed evidence of genotyping errors in the controls (departure from Hardy-Weinberg), e.g. IL10-rs1800896 and IL4R-rs1801275, were imputed 
using the Impute V2 software ${ }^{21}$. Information for imputation was obtained from all SNPs genotyped in our participants in the 100,000 bp in the vicinity of the gene, and using the CEU samples from the HapMap and 1000 Genomes projects (respectively, HapMap 43 release $28 \mathrm{CEU}$, phases 1, 2 and 3 [http://hapmap.ncbi.nlm.nih.gov], 1000 Genomes phase pilot 1-low coverage [http://www.1000genomes.org]) as reference panels. Inferred genotypes were further considered for analyses when the post-imputation probability reached at least $90 \%$. However, sensitivity analyses were conducted using a 0.80 cutoff. Additionally, the quality of imputation was assessed for each $\mathrm{SNP}$, by the Info and Certainty criteria provided by Impute V2 software.

The genotypes were analysed separately, and then assuming a dominant model of expression (carrying at least one variant allele $v s$. none). Since some SNPs in IL4 and IL10 (IL4-rs2070874 and rs2243250; IL10-rs1800871 and rs1800872) have been shown to be in linkage disequilibrium, the haplotypes were deduced from the genotypes. The haplotypes for IL4 rs2070874-rs2243250 were CC (reference haplotype) and TT (double variant haplotype), and those for IL10 rs1800896-rs1800871-rs1800872 were CGG (reference haplotype), TGG and the triple variant TAT haplotype.

\subsection{Statistical analyses}

For each SNP, the Hardy-Weinberg equilibrium test was systematically performed in the group of 442 controls of European ancestry, and there was no evidence of a departure from the equilibrium. Unconditional logistic regression models were used to compare cases and controls with regards to their history of asthma or eczema, and genotypes. All analyses presented hereafter were adjusted for a gender*age variable, birth order, maternal highest diploma, and professional category of the household ${ }^{20}$. Interactions were assessed using likelihood ratio tests.

\section{3. $\underline{\text { Results }}$}

\subsection{Study sample}

The table 1 shows a brief description of the subsample of genotyped children of European ancestry. The distribution of gender was not different in cases and controls, but controls tended to be globally older than ALL cases. Cases were more likely than controls to be first-born children, and not to have been breastfed. The parental socio-professional characteristics were differently distributed, with higher educational levels and higher professional category in the control group. Common precursor-B cell leukaemia was the most common subtype ( $\mathrm{n}=355$ ), with the group of genotyped cases also including less common subtypes, such as pro-B $(n=10)$, mature B-cell $(n=19)$, T-cell $(n=40)$ and other types of lymphoid leukaemia $(n=40)$.

\subsection{Association between asthma or eczema and childhood ALL}


In this subsample of 434 ALL cases and 442 controls genotyped and of European origin, asthma and eczema were both inversely associated with the occurrence of childhood ALL (respective OR=0.6 [0.4-1.1] and 0.8 [0.5-1.1]) (table 2), as observed in the whole ESCALE study ${ }^{18}$. These associations were also observed when considering a latency of 1 year, and when changing the definition of asthmatic children to those treated with anti-allergic, bronchodilators or corticoid drugs. Having a history of either asthma or eczema was significantly associated with childhood ALL with the same order of magnitude $(\mathrm{OR}=0.7$ [0.5-1.0]). Associations were unchanged when histories of asthma and eczema were mutually adjusted for.

\subsection{Association between candidate polymorphisms and childhood ALL}

Table 3 shows the associations between the candidate polymorphisms in IL13,IL10, IL4 and IL4R genes and childhood ALL. None of the genotypes of the candidate SNPs analysed separately were associated with childhood ALL. The IL4 double variant haplotype (TT haplotype) was little associated with childhood ALL $(\mathrm{OR}=1.3$ [0.9-1.8], $\mathrm{p}=0.14)$, but the IL10 TAT triple variant haplotype was not associated with ALL.

\subsection{Gene-gene and gene-environment interactions}

The analyses suggested a gene-gene interaction between IL4 TT haplotype and IL13-rs20541 (IOR 1.8, $\mathrm{p}=0.10$ ), between $I L 13$-rs20541 and IL10 TAT haplotype (IOR 0.6, $\mathrm{p}=0.10$ ), and between IL4 TT haplotype and $I L 4 R$-rs 1801275 (IOR 1.8, p=0.07), , despite lack of statistical significance (table 4).

The analyses of interaction between a reported medical history and the candidate polymorphisms are shown in table 5. The results suggested there might be an interaction between IL13-rs20541 and a medical history of asthma or eczema. Indeed, the inverse association between childhood ALL and asthma/eczema was only seen in the group of children carrying no variant allele $(\mathrm{OR}=0.5$ [0.4-0.8] vs. $\mathrm{OR}=1.1$ [0.6-1.9] in the carrier group [not shown], interaction test $\mathrm{p}=0.07$ ). There was also some evidence of an interaction with the IL10-TAT haplotype, with the association between a history of asthma or eczema and childhood ALL observed in those carrying the triple variant haplotype $(\mathrm{IOR}=0.5[0.2-1.0], \mathrm{p}$ interaction 0.04). There was no evidence of an interaction between asthma/eczema and $I L 4$ or $I L 4 R$ polymorphisms.

\subsection{Sensitivity analyses}

Similar patterns of interaction were observed after taking into account a one-year latency, and lowering the imputation probability cutoff to 0.80 .

All analyses repeated with a further adjustment for repeated infections in infancy, maternal pesticides use during pregnancy, paternal smoking before conception, familial history of cancer, and road traffic showed compatible estimates, although the association between a history of asthma or eczema and 
childhood ALL was weaker ( $\mathrm{OR}=0.8$ [0.6-1.1]). Adjusting all models for attendance to full-time day care before the age of 1 year did not change the results. We also repeated the analyses adjusting for the number of grandparents born in Europe (2,3 or 4) and the results did not change.

The associations between the various SNPs in $I L 4$ and $I L 10$ and asthma or eczema in the control group were compatible with the positive associations reported in previous literature, with OR estimates ranging between 1.2 and 1.4, although not reaching statistical significance (dominant model, data not shown). However, the association with IL13-rs20541 and IL4R-rs1801275 (OR=0.8 [0.5-1.2] and $\mathrm{OR}=0.9$ [0.6-1.4]) did not replicate the associations found in previous studies.

All analyses were repeated in the 422 cases and 434 controls whose mother had a copy of the medical record at the interview, and showed similar results.

\section{Discussion}

\subsection{Main results}

Not only do our results support an inverse association between childhood ALL and a reported history of asthma or eczema, but they suggest that this association could depend on the children's genotypes for Th2 cytokine genes. Indeed, in this study, the inverse association was essentially observed in individuals not carrying the variant IL13-rs20541 allele, and in those carrying the IL10 TAT haplotype.

\subsection{Strength and limits}

The registry-based methods used for the identification of the eligible cases and the high participation rate ensured that the recruitment of cases was nearly exhaustive. Only 41 leukaemia cases were not eligible for medical reasons, being dead or under palliative care, which is unlikely to have biased our results. Biological sampling was generally well accepted in this population-based study, and later decreases in numbers were mainly due to unsuccessful genotyping.

The controls were randomly selected from the general population with quotas on the sex and age distributions ensuring comparability with the cases. Moreover, the selection process made the control group representative of the general population in terms of region and number of children living in the household. In the control group, the age at recruitment, parental education level and professional category were related to the acceptance and success of the genotyping, the latter being probably due to the sampling method (saliva). These variables were considered potential confounders and all analyses were systematically adjusted for them. 
It was not possible to run a PCA to determine whether controls were of Caucasian origin because the genotyping platform used for the controls had much fewer SNPs than the one used for the cases. In order to limit the possibility of a population stratification bias, we however restricted our study to children with a European ancestry as derived from the country of birth of their grandparents. In the ESCALE study, this variable was found to be a good proxy for the Caucasian origin in the case group $^{20}$. The comparability of the different genotyping platforms used for cases and controls was assessed by re-genotyping 96 cases on the controls platform.

Because of the apparent discrepancy in published results between interview-based studies and two of the studies relying on medical and administrative data, misclassification bias is a particular concern when studying the relationship between a reported history of allergy and childhood ALL. In the ESCALE study, mothers were asked about the index child's medical history, and they were encouraged to use the child health record as a support for answering. Additional analyses showed robust results when restricted to children whose mother had the health record on hand during the interview. The questions about the age at onset and related treatments gave additional information to classify children on their medical history. The frequency of asthma in the ESCALE control group was very close to that observed in another French study ${ }^{22}$ (respectively $11.1 \%$ and $12.7 \%$ of the $11-14$ year-old children). Applying a one-year latency and restricting the definition of asthma to those under treatment did not change the magnitude of the association with childhood ALL, although leading to higher p-values. Because asthma and eczema can occur without a proper allergy and, conversely, allergy can manifest itself with other symptoms, the present results have a limited generalizability regarding allergy in childhood.

Candidate SNPs were selected for their potential association with allergy or symptoms, and their functional consequences. We used imputation to infer the genotypes for 4 SNPs in IL4 and IL10 that were not available in the case sample after genotyping, under strict quality criteria (Info and Certainty, post-imputation probability). To be considered for analysis, an individual genotype had to be imputed with a very high probability. Still, the sensitivity analyses showed that the results were robust to a lower imputation probability cutoff.

The power conditions to detect an interaction with $\mathrm{IOR}=2$ between a reported history of asthma or eczema (frequency $\approx 20 \%$ ) and the various candidate polymorphisms (frequency ranging from $25 \%$ to $40 \%$ ) in the subsample of 434 ALL cases and 442 controls were moderate, between $47 \%$ and $53 \%$. Our study might have suffered from under-power to detect interactions with small effect. However, our analyses highlighted two interactions between a reported history of asthma or eczema and both IL10 TAT haplotype and IL13-rs20541 alleles. Due to the number of tests performed, caution is required with regards to the interpretation of the p-values and these findings need replication.

\subsection{Comparison with previous literature}


Showing a negative association between ALL and history of asthma or eczema in the ESCALE study is in line with the results of most of the interview-based studies reporting on the association between allergy and childhood leukaemia ${ }^{23-26}$. A concern has been raised about the consistency of this inverse association, since two studies relying on objective data did not replicate this finding ${ }^{6,7}$. On the other hand, in a study using medical diagnoses from the children's medical record ${ }^{5}$, an inverse association was also found between childhood ALL and the definite diagnoses of allergy, eczema and hay fever. A meta-analysis by Linabery et $\mathrm{al}^{3}$ replicated the overall inverse association between atopy/allergy and childhood ALL, and underlined the lack of robustness of this association when taking into account a latency period. In the ESCALE study, the available data allowed taking into account a one-year latency and, although limited by numbers, those analyses showed an inverse association of the same order of magnitude.

The genotypic analyses showed a non-significantly raised OR related to the IL4 haplotype, but not with IL10 promoter haplotype that is related to a decrease in IL10 synthesis. In the NCCLS, Chang et $\mathrm{al}^{16}$ had found a slight association between three tag-SNPs in IL10 gene and childhood ALL that was not robust when taking into account multiple testing. In the same Californian study ${ }^{15}$, the analysis of blood samples taken at birth showed that cases featured lower IL10 levels than controls, whereas the levels of other Th1 and Th2 cytokines, including IL4 and IL13, were not different. Our results further suggest that the suspected negative association between childhood ALL and a medical history of asthma or eczema could be limited to children carrying certain genetic polymorphisms, such as the IL10 promoter TAT haplotype or the IL13-rs20541 GG genotype. Unlike with IL10, the interaction with IL13 could partly explain the discrepancies observed with the US $^{6}$ and Taiwanese ${ }^{7}$ studies. Indeed, genotyping from the 1000 Genomes project (phase 1) showed a lower proportion of IL13rs20541 GG genotype in people with Asian (42.7\%, ASN sample) or Mexican ancestry (19.7\%, MXL sample) than in those with European ancestry (60.0\%, CEU sample).

The inverse occurrence of allergy and childhood ALL suggested by epidemiological studies remains largely unclear. There is a growing body of evidence for a protective effect of a highly-active immune system against leukaemia, with studies having found an inverse association between childhood acute lymphoblastic leukaemia and allergy and early immune stimulations indicators such as daycare in infancy $^{2,27}$ and breastfeeding ${ }^{2,28}$. Immune responses are normally inhibited by the regulatory $\mathrm{T}$ cells (Treg), thus avoiding allergy and autoimmune diseases. As explained by the "reduced immune suppression" hypothesis, a lack of Treg stimulation could lead to inappropriately overactive Th1 and Th2 responses $^{29}$, which, one could hypothesize, could promote both allergy and the expansion of preleukaemic cells. Interestingly, this hypothesis aligns with the deficit in IL10, regulatory cytokine also produced by Treg cells, reported at birth in ALL cases by Chang and colleagues ${ }^{15}$. 
In conclusion, this study suggests that the association between allergic phenotypes and childhood ALL could be modified by genetic polymorphisms of Th2 cytokines such as IL13 and IL10. While these results warrant further replication, they provide further evidence for a reduced risk of ALL among children developing allergic symptoms, and suggest that this association could be related to immune suppression mechanisms involving IL10.

\section{Acknowledgements}

The authors are grateful to Claire Mulot, who was in charge of the biological collection at the Biological Resource Center of Saints-Pères, INSERM U775; the CEPH and the Centre National de Génotypage, who genotyped the cases; and IntegraGen, who genotyped the controls. We also thank Florence Demenais and the UMR-946 unit (Inserm-Université Paris Diderot) and Fondation Jean Dausset-CEPH for their support. The authors would also like to express their gratitude to: MarieHélène Da Silva, Christophe Steffen and Florence Menegaux (INSERM U1018, Environmental Epidemiology of Cancer), who contributed to the recruitment of the cases; Aurélie Guyot-Goubin and the staff of the French National Registry of Childhood Hematopoietic Malignancies, who contributed to case detection and verification; and Sabine Mélèze and Marie-Anne Noel (Institut CSA), who coordinated the selection of the controls.

The authors would also like to thank all of the Société Française de lutte contre les Cancers de l'Enfant et de l'Adolescent (SFCE) principal investigators: André Baruchel (Hôpital Saint-Louis/Hôpital Robert Debré, Paris), Claire Berger (Centre Hospitalier Universitaire, Saint-Etienne), Christophe Bergeron (Centre Léon Bérard, Lyon), Jean-Louis Bernard (Hôpital La Timone, Marseille), Yves Bertrand (Hôpital Debrousse, Lyon), Pierre Bordigoni (Centre Hospitalier Universitaire, Nancy), Patrick Boutard (Centre Hospitalier Régional Universitaire, Caen), Gérard Couillault (Hôpital d'Enfants, Dijon), Christophe Piguet (Centre Hospitalier Régional Universitaire, Limoges), AnneSophie Defachelles (Centre Oscar Lambret, Lille), François Demeocq (Hôpital Hôtel-Dieu, ClermontFerrand), Alain Fischer (Hôpital des Enfants Malades, Paris), Virginie Gandemer (Centre Hospitalier Universitaire - Hôpital Sud, Rennes), Dominique Valteau-Couanet (Institut Gustave Roussy, Villejuif), Jean-Pierre Lamagnere (Centre Gatien de Clocheville, Tours), Françoise Lapierre (Centre Hospitalier Universitaire Jean Bernard, Poitiers), Guy Leverger (Hôpital Armand-Trousseau, Paris), Patrick Lutz (Hôpital de Hautepierre, Strasbourg), Geneviève Margueritte (Hôpital Arnaud de Villeneuve, Montpellier), Françoise Mechinaud (Hôpital Mère et Enfants, Nantes), Gérard Michel (Hôpital La Timone, Marseille), Frédéric Millot (Centre Hospitalier Universitaire Jean Bernard, Poitiers), Martine Münzer (American Memorial Hospital, Reims), Brigitte Nelken (Hôpital Jeanne de Flandre, Lille), Hélène Pacquement (Institut Curie, Paris), Brigitte Pautard (Centre Hospitalier Universitaire, Amiens), Yves Perel (Hôpital Pellegrin Tripode, Bordeaux), Alain Pierre-Kahn (Hôpital Enfants Malades, Paris), Emmanuel Plouvier (Centre Hospitalier Régional, Besançon), Xavier 
Rialland (Centre Hospitalier Universitaire, Angers), Alain Robert (Hôpital des Enfants, Toulouse), Hervé Rubie (Hôpital des Enfants, Toulouse), Nicolas Sirvent (L'Archet, Nice), Christine Soler (Fondation Lenval, Nice), and Jean-Pierre Vannier (Hôpital Charles Nicolle, Rouen).

Funding: This work was supported by grants from INSERM, the Fondation de France, the Association pour la Recherche sur le Cancer (ARC), the Agence Française de Sécurité Sanitaire des Produits de Santé (AFSSAPS), the Agence Française de Sécurité Sanitaire de l'Environnement et du Travail (AFSSET), the association Cent pour sang la vie, the Institut National du Cancer (INCa), the Agence Nationale de la Recherche (ANR), and the Cancéropôle Ile de France.

The authors declare no conflict of interest. 
Table 1: Characteristics of the sample of genotyped cases and controls of European ancestry

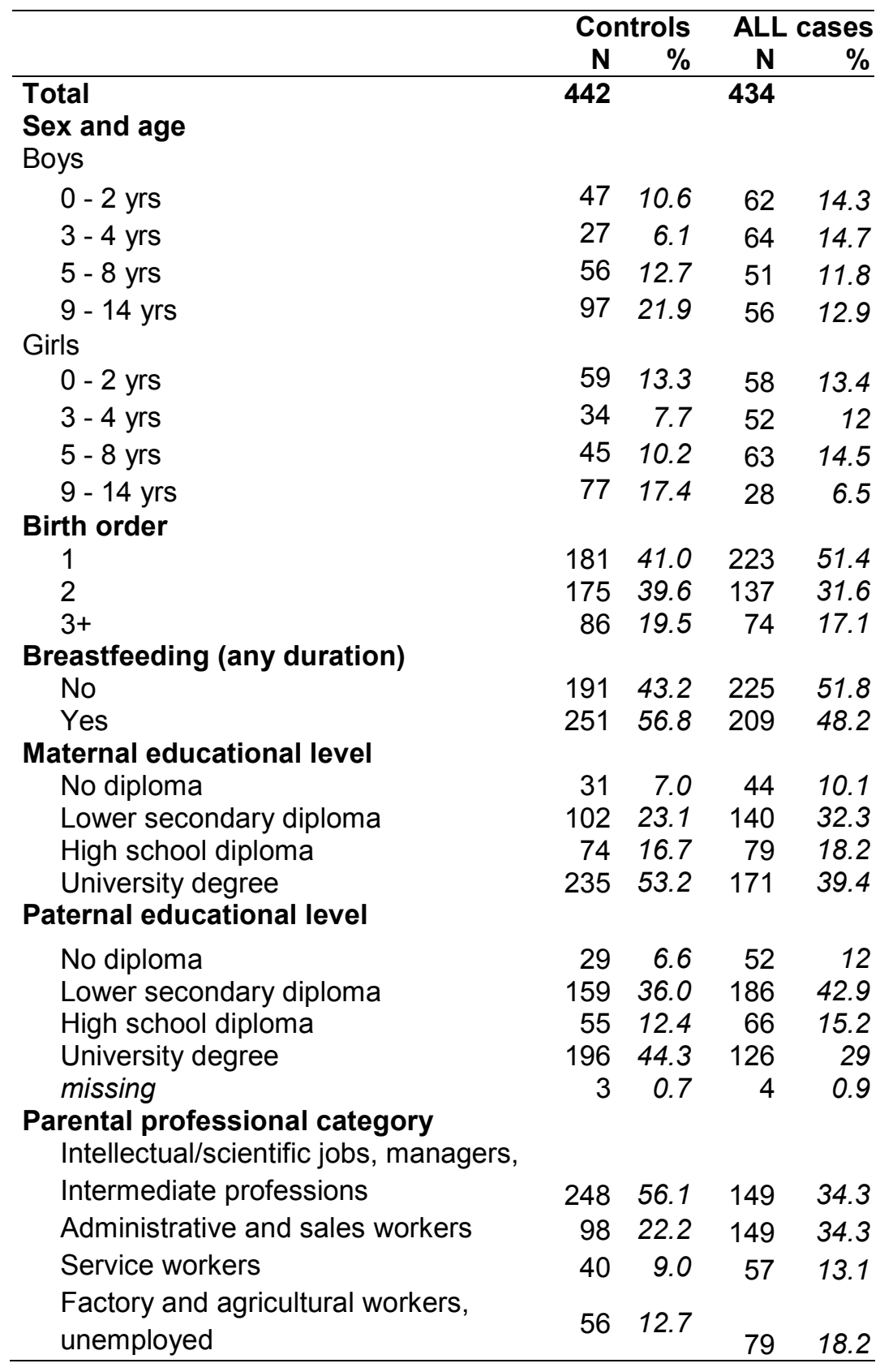


Table 2: Association between a reported history of asthma or eczema and childhood ALL

\begin{tabular}{|c|c|c|c|c|c|c|c|}
\hline & \multicolumn{2}{|c|}{$\begin{array}{c}\begin{array}{c}\text { Controls } \\
\mathrm{N}=442\end{array} \\
\text { (n) }\end{array}$} & \multicolumn{4}{|c|}{$\begin{array}{c}\text { ALL } \\
\mathrm{N}=434\end{array}$} & \multirow[b]{2}{*}{$\mathbf{p}$} \\
\hline & $\mathbf{n}$ & $\%$ & $\mathbf{n}$ & $\%$ & $\mathrm{OR}^{\mathrm{a}}$ & $95 \% \mathrm{Cl}$ & \\
\hline \multicolumn{8}{|l|}{ Reported asthma history } \\
\hline No & \multicolumn{2}{|c|}{39990.3} & \multicolumn{2}{|c|}{41094.5} & 1.0 & \multirow{3}{*}{$\begin{array}{l}\text { Ref. } \\
\text { [0.4-1.1] }\end{array}$} & \multirow{3}{*}{ ns } \\
\hline Yes & 42 & 9.5 & 24 & 5.5 & 0.6 & & \\
\hline missing & 1 & 0.2 & & & & & \\
\hline \multicolumn{8}{|l|}{ With a latency } \\
\hline No & \multicolumn{2}{|c|}{40491.4} & \multicolumn{2}{|c|}{41294.9} & 1.0 & \multirow{3}{*}{$\begin{array}{l}\text { Ref. } \\
\text { [0.4-1.3] }\end{array}$} & \\
\hline Yes & 36 & 8.1 & 22 & 5.1 & 0.7 & & ns \\
\hline missing & 2 & 0.5 & & & & & \\
\hline \multicolumn{8}{|l|}{ With treatment ${ }^{b}$} \\
\hline No & \multicolumn{2}{|c|}{40992.5} & \multicolumn{2}{|c|}{41595.6} & 1.0 & \multirow{3}{*}{$\begin{array}{l}\text { Ref. } \\
\text { [0.3-1.2] }\end{array}$} & \\
\hline Yes & 32 & 7.2 & 19 & 4.4 & 0.7 & & ns \\
\hline missing & 1 & 0.2 & & & & & \\
\hline \multicolumn{8}{|l|}{ Reported eczema history } \\
\hline No & \multicolumn{2}{|c|}{34678.3} & 355 & 81.8 & 1.0 & \multirow{3}{*}{$\begin{array}{l}\text { Ref. } \\
\text { [0.5-1.1] }\end{array}$} & \\
\hline Yes & 95 & 21.5 & 77 & 17.7 & 0.8 & & ns \\
\hline missing & & 0.2 & 2 & 0.5 & & & \\
\hline \multicolumn{8}{|l|}{ With a latency } \\
\hline No & \multicolumn{2}{|c|}{36382.1} & 359 & 82.7 & 1.0 & \multirow{3}{*}{$\begin{array}{l}\text { Ref. } \\
\text { [0.6-1.3] }\end{array}$} & \\
\hline Yes & 77 & 17.4 & 72 & 16.6 & 0.9 & & ns \\
\hline missing & & 0.5 & 3 & 0.7 & & & \\
\hline \multicolumn{8}{|c|}{ History of asthma and/or eczema } \\
\hline None & \multicolumn{2}{|c|}{31972.2} & 339 & 78.1 & 1.0 & \multirow{5}{*}{$\begin{array}{l}\text { Ref. } \\
{[0.3-1.3]} \\
{[0.5-1.1]} \\
{[0.2-1.4]}\end{array}$} & \multirow{5}{*}{ ns } \\
\hline Asthma without eczema & 27 & 6.1 & 16 & 3.7 & 0.6 & & \\
\hline Eczema without asthma & 79 & 17.9 & 69 & 15.9 & 0.8 & & \\
\hline Asthma and eczema & 15 & 3.4 & 8 & 1.8 & 0.6 & & \\
\hline Missing & 2 & 0.5 & 2 & 0.5 & & & \\
\hline Neither asthma, nor eczema & \multirow{2}{*}{\multicolumn{2}{|c|}{$\begin{array}{l}31972.2 \\
122 \quad 276\end{array}$}} & 339 & 78.1 & 1.0 & \multirow{3}{*}{$\begin{array}{l}\text { Ref. } \\
\text { [0.5-1.0] }\end{array}$} & \multirow{3}{*}{ * } \\
\hline Asthma or eczema & & & 93 & 21.4 & 0.7 & & \\
\hline missing & 1 & 0.2 & 2 & 0.5 & & & \\
\hline
\end{tabular}

a Odds ratios $(\mathrm{OR}) 95 \%$ confidence intervals $(95 \% \mathrm{Cl})$ estimated using a logistic regression model adjusted for a sex*age variable, maternal educational level, household socioprofessional category and birth order.

${ }^{b}$ treatments with antihistamines, corticoids or bronchodilators

ns: $p \geq 0.05,{ }^{*} p<0.05$ 
Table 3: Associations between candidate polymorphisms in IL13, IL4, IL10 and IL4R and childhood ALL

\begin{tabular}{|c|c|c|c|c|c|c|}
\hline & \multicolumn{2}{|c|}{$\begin{array}{c}\text { Controls } \\
N=442\end{array}$} & \multicolumn{4}{|c|}{$\begin{array}{c}\text { ALL } \\
\mathrm{N}=434\end{array}$} \\
\hline & $\mathbf{n}$ & $\%$ & $\mathbf{n}$ & $\%$ & OR $^{\mathrm{a}}$ & $95 \% \mathrm{Cl}$ \\
\hline \multicolumn{7}{|l|}{ IL13-rs20541 } \\
\hline & 290 & 65.6 & 268 & 61.8 & 1.0 & Ref. \\
\hline & 134 & 30.3 & 153 & 35.3 & 1.1 & {$[0.8-1.5]$} \\
\hline AA & 18 & 4.1 & 13 & 3.0 & 0.7 & {$[0.3-1.6]$} \\
\hline$A G+A A$ vs $G G$ & 152 & 34.4 & 166 & 38.2 & 1.0 & [0.8-1.4] \\
\hline \multicolumn{7}{|l|}{ IL4 - rs2070874 } \\
\hline & 334 & 75.6 & 296 & 68.2 & 1.0 & Ref. \\
\hline CT & 103 & 23.3 & 120 & 27.6 & 1.3 & [0.9-1.8] \\
\hline TT & 5 & 1.1 & 6 & 1.4 & 1.4 & [0.4-5.2] \\
\hline missing & & & 12 & 2.8 & & \\
\hline$C T+T T$ vs $C C$ & 108 & 24.4 & 126 & 29.0 & 1.3 & [0.9-1.8] \\
\hline \multicolumn{7}{|l|}{ IL4-rs2243250 } \\
\hline $\mathrm{CC}$ & 324 & 73.3 & 292 & 67.3 & 1.0 & Ref. \\
\hline CT & 112 & 25.3 & 119 & 27.4 & 1.1 & {$[0.8-1.6]$} \\
\hline TT & 6 & 1.4 & 6 & 1.4 & 1.0 & [0.3-3.7] \\
\hline missing & & & 17 & 3.9 & & \\
\hline$C T+T T$ vs $C C$ & 118 & 26.7 & 125 & 28.8 & 1.1 & [0.8-1.5] \\
\hline \multicolumn{7}{|l|}{ IL4 haplotype } \\
\hline$\geq 1 \mathrm{TT}$ & 108 & 24.4 & 125 & 28.8 & 1.3 & [0.9-1.8] \\
\hline \multicolumn{7}{|l|}{ IL10-rs1800896 } \\
\hline & 98 & 22.2 & 88 & 20.3 & 1.0 & Ref. \\
\hline & 211 & 47.7 & 215 & 49.5 & 1.1 & {$[0.8-1.7]$} \\
\hline TT & 133 & 30.1 & 131 & 30.2 & 1.0 & {$[0.7-1.5]$} \\
\hline$C T+T T$ vs $C C$ & 344 & 77.8 & 346 & 79.7 & 1.1 & [0.8-1.5] \\
\hline \multicolumn{7}{|l|}{ IL10-rs1800871 } \\
\hline GG & 261 & 59.0 & 229 & 52.8 & 1.0 & Ref. \\
\hline AG & 153 & 34.6 & 153 & 35.3 & 1.1 & {$[0.8-1.5]$} \\
\hline AA & 28 & 6.3 & 20 & 4.6 & 0.9 & {$[0.5-1.7]$} \\
\hline missing & & & 32 & 7.4 & & \\
\hline$A G+A A$ vs $G G$ & 181 & 41.0 & 173 & 39.9 & 1.1 & [0.8-1.5] \\
\hline \multicolumn{7}{|l|}{ IL10-rs 1800872} \\
\hline & 261 & 59.0 & 229 & 52.8 & 1.0 & Ref. \\
\hline GT & 153 & 34.6 & 170 & 39.2 & 1.2 & {$[0.9-1.7]$} \\
\hline TT & 28 & 6.3 & 24 & 5.5 & 1.1 & {$[0.6-2.1]$} \\
\hline missing & & & 11 & 2.5 & & \\
\hline$G T+T T$ vs $G G$ & 181 & 41.0 & 194 & 44.7 & 1.2 & [0.9-1.6] \\
\hline \multicolumn{7}{|l|}{ IL10 haplotypes } \\
\hline$\geq 1 \mathrm{TAT}$ & 181 & 41.0 & 173 & 39.9 & 1.1 & {$[0.8-1.5]$} \\
\hline$\geq 1 \mathrm{TGG}$ & 226 & 51.1 & 198 & 45.6 & 0.9 & [0.6-1.1] \\
\hline \multicolumn{7}{|l|}{ IL4R-rs1801275 } \\
\hline & 274 & 62.0 & 281 & 64.7 & 1.0 & Ref. \\
\hline AG & 154 & 34.8 & 135 & 31.1 & 0.8 & {$[0.6-1.2]$} \\
\hline GG & 14 & 3.2 & 18 & 4.1 & 1.3 & [0.6-2.9] \\
\hline$A G+G G$ vs $A A$ & 168 & 38.0 & 153 & 35.3 & 0.9 & {$[0.7-1.2]$} \\
\hline
\end{tabular}

a Odds ratios (OR) $95 \%$ confidence intervals $(95 \% \mathrm{Cl})$ estimated using a logistic regression model were adjusted for a sex*age variable, maternal educational level, household socioprofessional category and birth order. 
Table 4: Gene*gene interaction analyses for the candidate polymorphisms in IL13, IL4, IL10 and IL4R, in childhood ALL

\begin{tabular}{|c|c|c|c|c|c|}
\hline & \multicolumn{5}{|c|}{ Case-control models } \\
\hline & \multicolumn{2}{|c|}{$\begin{array}{c}\text { Without } \\
\text { interaction }\end{array}$} & \multicolumn{3}{|c|}{ With interaction } \\
\hline & OR & $95 \% \mathrm{Cl}$ & OR & $95 \% \mathrm{Cl}$ & p int \\
\hline \multicolumn{6}{|l|}{ IL13-rs 20541 x IL4 TT haplotype } \\
\hline Variant IL13 rs20541 & 1.0 & [0.7-1.4] & 0.8 & [0.6-1.2] & \\
\hline IL4 TT haplotype carrier & 1.3 & {$[0.9-1.8]$} & 1.0 & {$[0.6-1.6]$} & \\
\hline Variant IL 13-rs20541 x IL4 haplotype & & & 1.8 & [0.9-3.5] & 0.10 \\
\hline \multicolumn{6}{|l|}{ IL13-rs20541 x IL10 TAT haplotype } \\
\hline Variant IL13 rs20541 & 1.1 & [0.8-1.4] & 1.3 & [0.9-2.0] & \\
\hline IL10 TAT haplotype carrier & 1.1 & {$[0.8-1.5]$} & 1.3 & [0.9-1.9] & \\
\hline \multirow{2}{*}{\multicolumn{6}{|c|}{ IL13-rs20541 x IL4R-rs1801275 }} \\
\hline & & & & & \\
\hline Variant IL13 rs20541 & 1.0 & {$[0.8-1.4]$} & 0.9 & {$[0.6-1.4]$} & \\
\hline Variant IL4R rs 1801275 & 0.9 & [0.7-1.2] & 0.8 & [0.5-1.2] & \\
\hline Variant IL $13 \times$ variant IL4R & & & 1.3 & {$[0.7-2.5]$} & $n s$ \\
\hline \multicolumn{6}{|l|}{ IL4 TT haplotype x IL10 TAT haplotype } \\
\hline IL4 TT haplotype carrier & 1.3 & [1.0-1.9] & 1.5 & {$[1.0-2.3]$} & \\
\hline IL10 TAT haplotype carrier & 1.1 & [0.8-1.5] & 1.2 & [0.8-1.6] & \\
\hline IL4 haplotype x IL10 haplotype & & & 0.8 & {$[0.4-1.5]$} & $n s$ \\
\hline \multicolumn{6}{|l|}{ IL4 TT haplotype x IL4R-rs1801275 } \\
\hline IL4 TT haplotype carrier & 1.3 & [0.9-1.8] & 1.0 & {$[0.7-1.5]$} & \\
\hline Variant IL $4 R$ rs 1801275 & 0.9 & {$[0.7-1.2]$} & 0.8 & {$[0.5-1.1]$} & \\
\hline $\begin{array}{l}\text { IL4 haplotype } \times \text { variant IL4R } \\
\text { IL10 TAT haplotype } \times \text { IL4R-rs } 1801275\end{array}$ & & & 1.8 & {$[0.9-3.6]$} & 0.07 \\
\hline IL10 TAT haplotype carrier & 1.1 & {$[0.8-1.5]$} & 1.2 & {$[0.8-1.7]$} & \\
\hline Variant IL $4 R$ rs 1801275 & 0.9 & [0.6-1.2] & 0.9 & {$[0.6-1.4]$} & \\
\hline IL10 haplotype $x$ variant IL4R & & & 0.8 & {$[0.4-1.5]$} & $n s$ \\
\hline
\end{tabular}

Odds ratios $(\mathrm{OR})$ and $95 \%$ confidence intervals $(95 \% \mathrm{Cl})$ estimated using a logistic regression model adjusted for a sex*age variable, maternal educational level, household socioprofessional category and birth order.

$p$ int: $p$ for interaction test; $n s: p>0.10$ 
Table 5: Interaction analyses between the candidate polymorphisms and a reported history of asthma or eczema, in childhood ALL

\begin{tabular}{|c|c|c|c|c|c|c|c|c|c|}
\hline & \multicolumn{3}{|c|}{ Asthma } & \multicolumn{3}{|c|}{ Eczema } & \multicolumn{3}{|c|}{ Asthma or eczema } \\
\hline & OR & $95 \% \mathrm{Cl}$ & p int & OR & $95 \% \mathrm{Cl}$ & p int & OR & $95 \% \mathrm{Cl}$ & $p$ int \\
\hline \multicolumn{10}{|l|}{ IL13-rs20541 } \\
\hline Medical history vs no & 0.5 & {$[0.3-1.1]$} & & 0.6 & {$[0.4-1.0]$} & & 0.6 & {$[0.4-0.9]$} & \\
\hline$\geq 1$ variant allele vs none & 1.0 & {$[0.7-1.4]$} & & 0.9 & {$[0.7-1.3]$} & & 0.9 & {$[0.6-1.2]$} & \\
\hline Interaction history $\mathrm{x}$ allele & 1.8 & {$[0.5-6.0]$} & $n s$ & 1.7 & {$[0.8-3.7]$} & $n s$ & 1.9 & {$[0.9-3.8]$} & 0.07 \\
\hline \multicolumn{10}{|l|}{ IL4-rs2070874 } \\
\hline Medical history vs no & 0.6 & {$[0.3-1.3]$} & & 0.7 & {$[0.5-1.1]$} & & 0.7 & {$[0.4-1.0]$} & \\
\hline$\geq 1$ variant allele vs none & 1.3 & {$[0.9-1.9]$} & & 1.3 & {$[0.9-1.9]$} & & 1.3 & {$[0.9-1.9]$} & \\
\hline Interaction history $\mathrm{x}$ allele & 0.9 & {$[0.3-2.9]$} & $n s$ & 0.9 & {$[0.4-2.0]$} & $n s$ & 1.1 & {$[0.5-2.2]$} & ns \\
\hline \multicolumn{10}{|l|}{ IL4-rs2243250 } \\
\hline Medical history vs no & 0.7 & {$[0.3-1.3]$} & & 0.7 & [0.5-1.2] & & 0.7 & {$[0.4-1.0]$} & \\
\hline$\geq 1$ variant allele vs none & 1.2 & [0.8-1.6] & & 1.1 & {$[0.8-1.7]$} & & 1.1 & [0.8-1.6] & \\
\hline Interaction history $\mathrm{x}$ allele & 0.8 & {$[0.2-2.8]$} & $n s$ & 0.9 & {$[0.4-2.0]$} & $n s$ & 1.1 & {$[0.5-2.3]$} & $n s$ \\
\hline \multicolumn{10}{|l|}{ IL4 TT haplotype } \\
\hline Medical history vs no & 0.6 & [0.3-1.3] & & 0.7 & {$[0.5-1.2]$} & & 0.7 & {$[0.4-1.0]$} & \\
\hline$\geq 1$ variant allele vs none & 1.3 & {$[0.9-1.9]$} & & 1.3 & {$[0.9-1.9]$} & & 1.3 & {$[0.9-1.9]$} & \\
\hline Interaction history $\mathrm{x}$ allele & 0.9 & {$[0.3-2.9]$} & $n s$ & 0.9 & {$[0.4-2.0]$} & $n s$ & 1.0 & {$[0.5-2.2]$} & $n s$ \\
\hline \multicolumn{10}{|l|}{ IL10-rs1800896 } \\
\hline Medical history vs no & 0.9 & {$[0.3-2.6]$} & & 0.9 & [0.4-2.2] & & 0.8 & {$[0.4-1.7]$} & \\
\hline$\geq 1$ variant allele vs none & 1.1 & [0.8-1.6] & & 1.2 & {$[0.8-1.7]$} & & 1.2 & {$[0.8-1.7]$} & \\
\hline Interaction history x allele & 0.7 & {$[0.2-2.4]$} & $n s$ & 0.8 & [0.3-1.9] & $n s$ & 0.8 & {$[0.4-2.0]$} & $n s$ \\
\hline \multicolumn{10}{|l|}{ IL10-rs1800871 } \\
\hline Medical history vs no & 1.1 & {$[0.5-2.3]$} & & 0.9 & {$[0.6-1.5]$} & & 1.0 & {$[0.6-1.5]$} & \\
\hline$\geq 1$ variant allele vs none & 1.2 & {$[0.9-1.6]$} & & 1.2 & {$[0.9-1.7]$} & & 1.3 & {$[0.9-1.8]$} & \\
\hline Interaction history $\mathrm{x}$ allele & 0.3 & {$[0.1-1.0]$} & 0.04 & 0.6 & {$[0.3-1.2]$} & $n s$ & 0.5 & {$[0.2-1.0]$} & 0.04 \\
\hline \multicolumn{10}{|l|}{ IL10-rs1800872 } \\
\hline Medical history vs no & 1.1 & {$[0.5-2.3]$} & & 0.9 & {$[0.6-1.5]$} & & 1.0 & {$[0.6-1.5]$} & \\
\hline$\geq 1$ variant allele vs none & 1.4 & {$[1.0-1.8]$} & & 1.4 & {$[1.0-1.9]$} & & 1.5 & {$[1.0-2.0]$} & \\
\hline Interaction history $\mathrm{x}$ allele & 0.2 & {$[0.1-0.8]$} & 0.02 & 0.6 & {$[0.3-1.3]$} & $n s$ & 0.5 & {$[0.3-1.0]$} & 0.06 \\
\hline \multicolumn{10}{|l|}{ IL10 TAT haplotype } \\
\hline Medical history vs no & 1.1 & {$[0.5-2.3]$} & & 0.9 & {$[0.6-1.5]$} & & 1.0 & {$[0.6-1.5]$} & \\
\hline$\geq 1$ variant allele vs none & 1.2 & {$[0.9-1.6]$} & & 1.2 & {$[0.9-1.7]$} & & 1.3 & [0.9-1.8] & \\
\hline Interaction history $\mathrm{x}$ allele & 0.3 & {$[0.1-1.0]$} & 0.04 & 0.6 & {$[0.3-1.2]$} & $n s$ & 0.5 & {$[0.2-1.0]$} & 0.04 \\
\hline \multicolumn{10}{|l|}{ IL4R-rs1801275 } \\
\hline Medical history vs no & 0.4 & {$[0.2-0.8]$} & & 0.8 & {$[0.5-1.3]$} & & 0.7 & {$[0.4-1.0]$} & \\
\hline$\geq 1$ variant allele vs none & 0.8 & {$[0.6-1.1]$} & & 0.9 & {$[0.7-1.3]$} & & 0.9 & {$[0.6-1.2]$} & \\
\hline Interaction history $\mathrm{x}$ allele & 3.7 & {$[1.1-12.6]$} & 0.04 & 0.8 & {$[0.4-1.8]$} & ns & 1.2 & {$[0.6-2.4]$} & ns \\
\hline
\end{tabular}

Odds ratios $(\mathrm{OR})$ and $95 \%$ confidence intervals $(95 \% \mathrm{Cl})$ estimated using a logistic regression model adjusted for a sex*age variable, maternal educational level, household socioprofessional category and birth order.

$p$ int: $p$ for interaction test; $n s: p>0.10$ 


\section{References}

1. Greaves MF. Speculations on the cause of childhood acute lymphoblastic leukemia. Leukemia. 1988 Feb;2(2):120-5

2. Rudant J, Lightfoot T, Urayama KY, Petridou E, Dockerty JD, Magnani C, et al. Childhood acute lymphoblastic leukemia and indicators of early immune stimulation: a Childhood Leukemia International Consortium study. American journal of epidemiology. 2015 Apr 15;181(8):549-62

3. Linabery $A M$, Jurek $A M$, Duval $S$, Ross JA. The association between atopy and childhood/adolescent leukemia: a meta-analysis. American journal of epidemiology. $2010 \mathrm{Apr}$ 1;171(7):749-64

4. Linabery AM, Spector LG. Invited commentary: childhood acute lymphoblastic leukemia and allergies: biology or bias? American journal of epidemiology. 2012 Dec 1;176(11):979-83; discussion 84-5

5. Hughes AM, Lightfoot T, Simpson J, Ansell P, McKinney PA, Kinsey SE, et al. Allergy and risk of childhood leukaemia: results from the UKCCS. Int J Cancer. 2007 Aug 15;121(4):819-24

6. Spector L, Groves F, DeStefano F, Liff J, Klein M, Mullooly J, et al. Medically recorded allergies and the risk of childhood acute lymphoblastic leukaemia. Eur J Cancer. 2004 Mar;40(4):579-84

7. Chang JS, Tsai YW, Tsai CR, Wiemels JL. Allergy and risk of childhood acute lymphoblastic leukemia: a population-based and record-based study. American journal of epidemiology. 2012 Dec 1;176(11):970-8

8. Lariou MS, Dikalioti SK, Dessypris N, Baka M, Polychronopoulou S, Athanasiadou-Piperopoulou F, et al. Allergy and risk of acute lymphoblastic leukemia among children: a nationwide case control study in Greece. Cancer Epidemiol. 2013 Apr;37(2):146-51

9. Nunez-Enriquez JC, Fajardo-Gutierrez A, Buchan-Duran EP, Bernaldez-Rios R, Medina-Sanson A, Jimenez-Hernandez $E$, et al. Allergy and acute leukaemia in children with Down syndrome: a population study. Report from the Mexican inter-institutional group for the identification of the causes of childhood leukaemia. Br J Cancer. 2013 Jun 11;108(11):2334-8

10. Loza MJ, Chang BL. Association between Q551R IL4R genetic variants and atopic asthma risk demonstrated by meta-analysis. J Allergy Clin Immunol. 2007 Sep;120(3):578-85

11. Cui L, Jia J, Ma CF, Li SY, Wang YP, Guo XM, et al. IL-13 polymorphisms contribute to the risk of asthma: a meta-analysis. Clin Biochem. 2012 Mar;45(4-5):285-8

12. Nie W, Fang Z, Li B, Xiu QY. Interleukin-10 promoter polymorphisms and asthma risk: a metaanalysis. Cytokine. 2012 Dec;60(3):849-55

13. Yang HJ. Association between the interleukin-4 gene C-589T and C+33T polymorphisms and asthma risk: a meta-analysis. Arch Med Res. 2013 Feb;44(2):127-35

14. Genuneit J, Cantelmo JL, Weinmayr G, Wong GW, Cooper PJ, Riikjarv MA, et al. A multi-centre study of candidate genes for wheeze and allergy: the International Study of Asthma and Allergies in Childhood Phase 2. Clin Exp Allergy. 2009 Dec;39(12):1875-88

15. Chang JS, Zhou M, Buffler PA, Chokkalingam AP, Metayer C, Wiemels JL. Profound deficit of IL10 at birth in children who develop childhood acute lymphoblastic leukemia. Cancer Epidemiol Biomarkers Prev. 2011 Aug;20(8):1736-40

16. Chang JS, Wiemels JL, Chokkalingam AP, Metayer C, Barcellos LF, Hansen HM, et al. Genetic polymorphisms in adaptive immunity genes and childhood acute lymphoblastic leukemia. Cancer Epidemiol Biomarkers Prev. 2010 Sep;19(9):2152-63 
17. Lo WJ, Chang WS, Hsu HF, Ji HX, Hsiao CL, Tsai CW, et al. Significant Association of Interleukin-10 Polymorphisms with Childhood Leukemia Susceptibility in Taiwan. In Vivo. 2016 MayJun;30(3):265-9

18. Rudant J, Orsi L, Menegaux F, Petit A, Baruchel A, Bertrand $Y$, et al. Childhood acute leukemia, early common infections, and allergy: The ESCALE Study. American journal of epidemiology. 2010 Nov 1;172(9):1015-27

19. Bonaventure A, Rudant J, Goujon-Bellec S, Orsi L, Leverger G, Baruchel A, et al. Childhood acute leukemia, maternal beverage intake during pregnancy, and metabolic polymorphisms. Cancer causes \& control : CCC. 2013 Apr;24(4):783-93

20. Bonaventure A, Goujon-Bellec S, Rudant J, Orsi L, Leverger G, Baruchel A, et al. Maternal smoking during pregnancy, genetic polymorphisms of metabolic enzymes, and childhood acute leukemia: the ESCALE Study (SFCE). Cancer causes \& control : CCC. 2012 Feb;23(2):329-45

21. Howie BN, Donnelly P, Marchini J. A flexible and accurate genotype imputation method for the next generation of genome-wide association studies. PLoS Genet. 2009 Jun;5(6):e1000529

22. Delmas M, Leynaert B, Com-Ruelle L, Annesi-Maesano I, Fuhrman C. Asthme : prévalence et impact sur la vie quotidienne - Analyse des données de l'enquête décennale santé 2003 de I'Insee. 2008.

23. Wen $\mathrm{W}$, Shu XO, Linet MS, Neglia JP, Potter JD, Trigg ME, et al. Allergic disorders and the risk of childhood acute lymphoblastic leukemia (United States). Cancer causes \& control : CCC. 2000 Apr;11(4):303-7

24. Schuz J, Morgan G, Bohler E, Kaatsch P, Michaelis J. Atopic disease and childhood acute lymphoblastic leukemia. Int J Cancer. 2003 Jun 10;105(2):255-60

25. Jourdan-Da Silva N, Perel Y, Mechinaud F, Plouvier E, Gandemer V, Lutz P, et al. Infectious diseases in the first year of life, perinatal characteristics and childhood acute leukaemia. $\mathrm{Br} J$ Cancer. 2004 Jan 12;90(1):139-45

26. Rosenbaum PF, Buck GM, Brecher ML. Allergy and infectious disease histories and the risk of childhood acute lymphoblastic leukaemia. Paediatr Perinat Epidemiol. 2005 Mar;19(2):152-64

27. Urayama KY, Buffler PA, Gallagher ER, Ayoob JM, Ma X. A meta-analysis of the association between day-care attendance and childhood acute lymphoblastic leukaemia. Int J Epidemiol. 2010 Jun;39(3):718-32

28. Martin RM, Gunnell D, Owen CG, Smith GD. Breast-feeding and childhood cancer: A systematic review with metaanalysis. Int J Cancer. 2005 Dec 20;117(6):1020-31

29. Romagnani S. The increased prevalence of allergy and the hygiene hypothesis: missing immune deviation, reduced immune suppression, or both? Immunology. 2004 Jul;112(3):352-63 